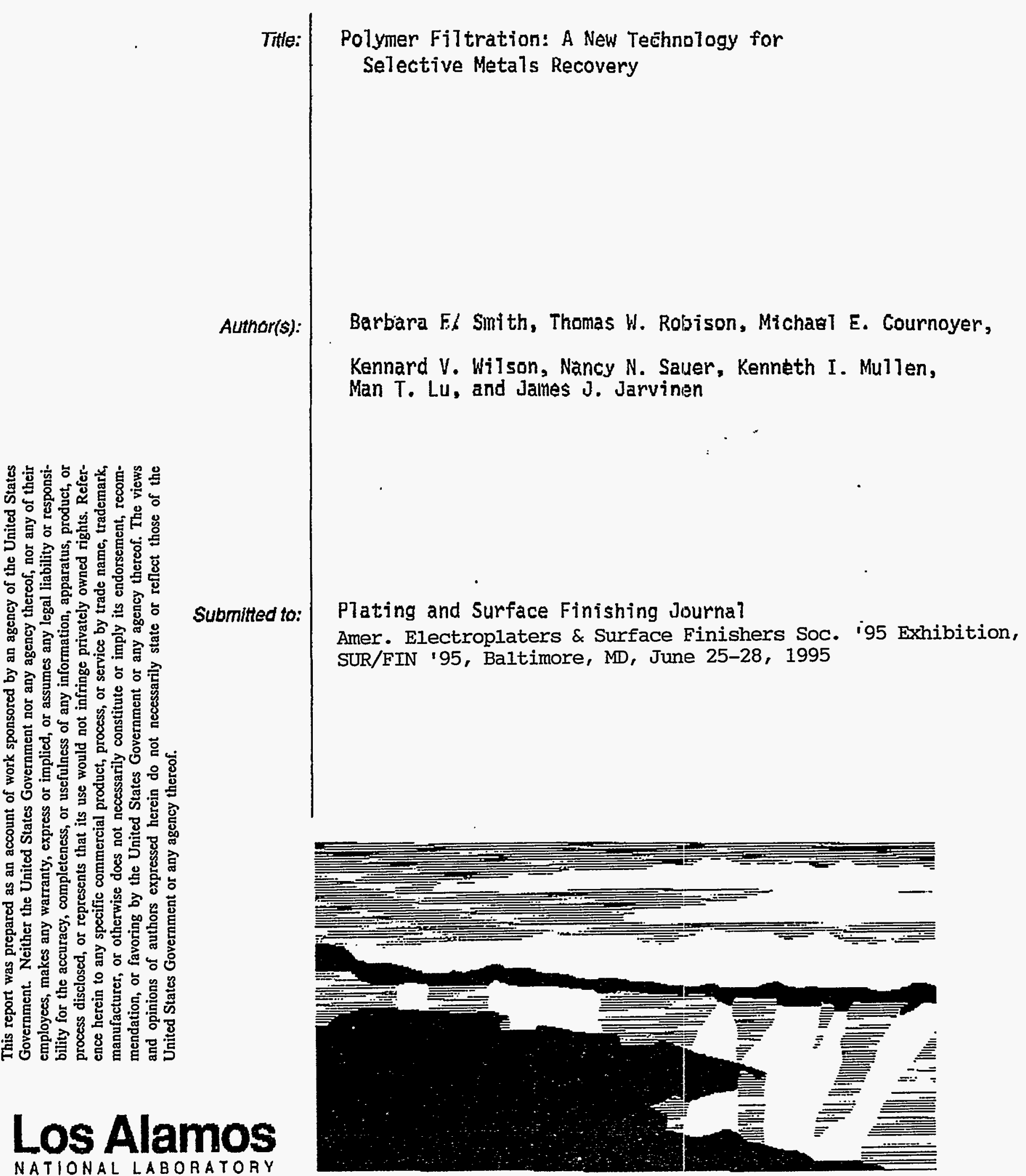

Los Alamos National Laboratory, an affirmativo actionvequal opponuläly emplofyer, is opsrated by the University of Callfornla lor the U.S. Department of Enargy

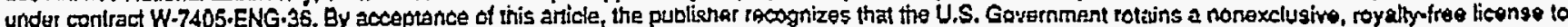
publibh or raproduce the publishod form of this confribution, or to ellow others to do so, for U.S. Government purposes. The Los Alamos National Laboralory requesrs inat the publisher identity this article as work pertormed under the auspices of the U.S. Department of Energy. 


\section{DISCLAIMER}

Portions of this document may be illegible in electronic image products. Images are produced from the best available original document. 


\title{
Polymer Filtration: A New Technology for Selective Metals Recovery
}

\author{
By Barbara F. Smith, Thomas W. Robison, Michael E. Coumoyer, Kennard V. Wilson, \\ Nancy N. Sauer, Kenneth I. Mullen, Man T. Lu, and James J. Jarvinen
}

\begin{abstract}
A new technology is under development to selectively recover regulated metal ions from electroplating rinse waters. The electroplating metal ions are recovered in a concentrated form with the appropriate counter ions ready for return to the original electroplating bath. The technology is based on the use of specially designed water-soluble polymers that selectively bind with the metal ions in the rinse bath. The polymers have such a large molecular weight that they can be physically separated using available ultrafiltration technology. The advantages of this technology are high metal-ion selectivity with no sludge formation, rapid processing, low energy, low capital costs, and small size. We have tested and demonstrated the recovery of zinc and nickel (using a new alloy electroplating bath designed to replace cadmium) from rinse waters. The metal-ion concentrate was returned to the original electroplating bath. Impurity metals such as iron and copper were removed from the zinc-nickel concentrate and were not returned to the electroplating bath. Test panels were electroplated as a baseline and compared with new test panels electroplated after the addition of the recovered zinc and nickel. No adverse effects on the bath integrity were observed. The rinse water was depleted of the electroplating metals to less than $0.1 \mathrm{ppm}$ zinc and nickel, and the water was satisfactory for discharge to the sewer system.
\end{abstract}

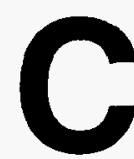
losed-loop, metal-finishing systems and zerodischarge goals require different approaches to waste-water handling. Traditional precipitation technologies cannot be improved upon enough to meet today's discharge requirements. ${ }^{1} \mathrm{New}$ selective metal-ion recovery systems are required to recover metal value, to reduce cost and liability of toxic sludge formation and burial, and to reduce reagent, water, and sewer costs.

Smaller point-source treatment units may be preferred because they use less energy than the end-ofpipe systems traditionally used in treating metal-ion mixtures. By focusing on the point source, the chemistry of metal separations can be optimized for the particular plating line, thereby optimizing the removal and recovery of the metal ions of interest. This approach contrasts sharply with precipitation, which uses one set of conditions; however, optimum conditions for one group of metals is not: appropriate for others, and the metal-discharge concentrations can exceed EPA limits. Soluble chelators often occur in electroplating waste waters, which further complicates the precipitation process and adds to the variability of metal-ion concentration in the discharge waters. Additionally, sludge handling and disposal is becoming expensive as burial requirements increase. The production of sludge is a potential liability for electroplating facility owners.

Newer treatment approaches involve multiple or tandem technologies to reach the near-zero discharge requirements. Two proposed approaches are: reverse osmosis with electro-recovery and ion exchange with electro-recovery followed by evaporation. Other technologies that can be applied include carbon treatment, recrystallization, electrodialysis, and chelating ion exchange. The tandern technologies chosen depend upon the ultimate goal: for example, water is to be recovered, the metal value is to be recovered, sludge is to be eliminated, discharge limits are to be consistently met, or all of the above.

We have been evaluating a new technology that is nonsludge-forming and can selectively recover metalion value for direct re-use in the original electroplating bath.

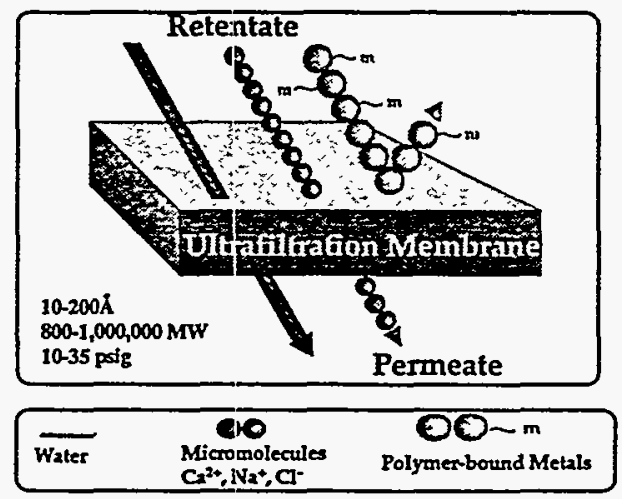

Fig. 1-Polymer filtration.

\section{Polymer Filtration (FF)}

The use of water-soluble metal-binding polymers in combination with ultrafiltration has been proposed for the recovery of metal ions from dilute solutions." Metal-ion concentration/separation, as shown in Fig. 1, is based on size exclusion with retention (or

\footnotetext{
The principle idea of Polymer Filtration of metal ions was first proposed by A. S. Michaels, Ultrafiltration, in: Advances in Separation and Punfication, E.S. Perry (Ed.), John Wiley, New York, NY, 1968.
} 
membrane rejection) of metal ions bound to the polymer, while smaller unbound species in solution are able to freely pass through the pores of the ultrafiltration membrane. ${ }^{2-5}$ The homogeneity of PF separation processes has the advantage of rapid kinetics not ordinarily found in heterogeneous systems such as ion exchange chromatography. Mechanical stability of the polymer is not required as it is with resin-based separations systems.

The relative efficiency with which an ultrafiltration (UF) membrane retains or rejects a species can be determined experimentally with each species being assigned a numerical value between 0 and 1 -called the rejection coefficient $(\sigma)$. A rejection coefficient of 0 means that the species freely passes through an UF membrane (permeate) while species with a rejection coefficient of 1 are completely retained (retentate). The observation is that the small metal ions will freely pass through the membrane $(\sigma=0)$ unless the effective size is temporarily increased $(\sigma=1)$. In the case of a polymer/metal-ion complex in which the polymer $(P)$ is physically too large to pass through the ultrafiltration membrane, the rejection coefficient of the metal ions $\left(\mathrm{M}^{\mathrm{n}+}\right)$ in the presence of a complexing polymer is a reflection of the equilibrium or stability constant $\left(K_{s}\right)$ of the complex, which is a measure of the affinity of the polymer for a metal ion.

$$
\begin{aligned}
P+M^{n+} & \rightleftharpoons P^{n+} \\
K_{s} & =\frac{\left[P M^{n+}\right]}{[P]\left[P M^{n+}\right]}
\end{aligned}
$$

Generally, there are two modes of operation in ultrafiltration." The first is the concentration mode, schematically shown in Fig. 2 , where the volume in the retentate is reduced by simple ultrafiltration. The final concentration of any species in solution can be determined by

$$
c_{f}=c_{0} \cdot\left(\frac{v_{0}}{v_{f}}\right)^{\sigma}
$$

where $C_{f}$ is the final concentration of the species, $C_{0}$ the initial concentration, $V_{0}$ the initial volume of solution, and $V_{f}$ the final volume. If the rejection coefficient of the species is 1 , as would be the case for the watersoluble metal-binding polymers, then (2) simplifies to

$$
\mathrm{C}_{\mathrm{f}}=\mathrm{C}_{\mathrm{o}} \cdot \frac{\mathrm{V}_{\mathrm{o}}}{\mathrm{V}_{\mathrm{f}}}
$$

For two species in solution, a polymeric/metal-ion species $(P)$ and a micromolecular impurity $(A)$, where $\sigma_{p}>>\sigma_{a}$, the ultrafiltration of the solution should result in the concentration and enrichment of $P$ based on

$$
\left(\frac{c_{A}}{c_{p}}\right]_{f}=\left(\frac{c_{A}}{c_{p}}\right]_{0} \cdot\left(\frac{v_{0}}{v_{f}}\right)^{-\left(\sigma_{a}-\sigma_{p}\right)}
$$

Ultrafiltration is the basis for a significant degree of purification during concentration of polymer/metal-ion complexes in solution by PF.

The second mode of an ultrafiltration operation is diafiltration (Fig. 3). As permeate is generated, pure water is added to the retentate at the same rate so as to maintain a constant volume. In the diafiltration mode, the lower molecular weight species in solution are removed at a maximum rate when the rejection coefficient equals 0 . The retentate is, in effect, washed free of smaller solute. Theoretically, the percent solute (any dissolved species) remaining in the retentate can be calculated by using Eq. (5)

$$
C_{f}=C_{0} \cdot e^{-\frac{V_{w}}{V_{0}}(1-\sigma)}
$$

where $V_{w}$ is the volurne of solute free liquid (volumeequivalents) added, which also equals the amount of permeate processed.

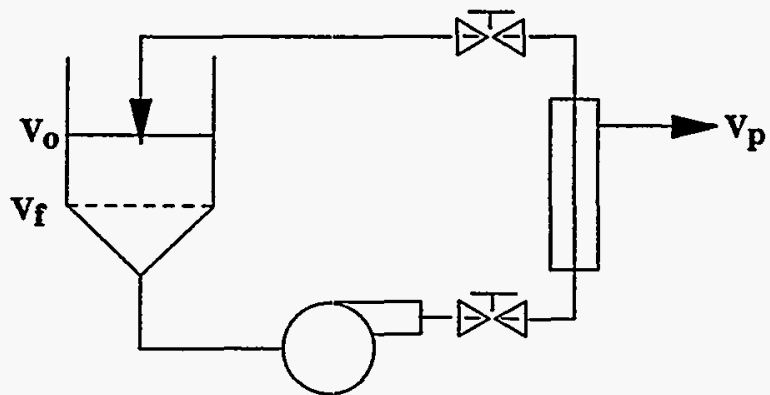

Fig. 2-Schematic of concentration by ultrafiltration.

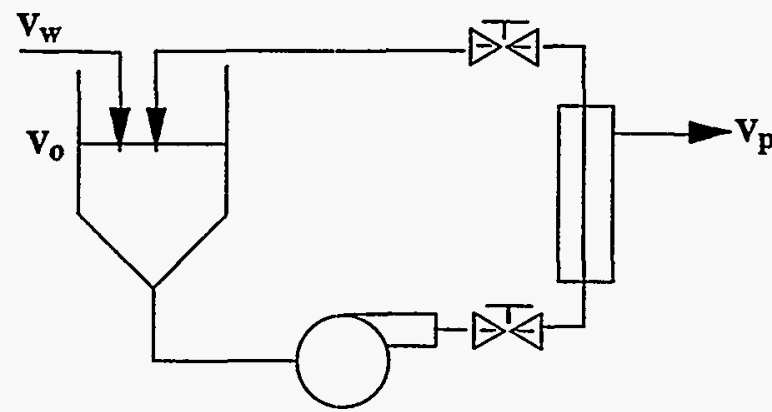

Fig. 3-Schematic of the diafiltration process.

Table 1 gives the correlation between solute removed and the percent solute remaining during a diafiltration process, assuming $\sigma=0$ as a function of the dilution ratio. From the table it can be seen that theoretically, after 5 volume-equivalents of processed solution, $99.3 \%$ of the lower molecular weight species should be removed. Experimentally, however, rejection coefficients of 0.0 are not ordinarily observed in PF. Even the smallest of interactions between the solute and the water-soluble polymer or the ultrafiltration membrane will give a small retention value. The effects of various rejection coefficients on the percent solute retained during a diafiltration process are shown graphically in Fig. 4. The curves for low retention coefficients

\footnotetext{
- For a general discussion on the ultrafiltration process see: M. Cheryan, Ultrafiltration Handbook, Technomic, Lancaster, United Kingdom, 1986. See also Winston, W. S., and Sirkar, K. K.(Eds.), Membrane Handbook, Van Nostrand Reinhold, N.Y., (1992)
} 
follow an exponential decay with each additional volume-equivalent giving diminishing returns in percent solute removed, while higher rejection coefficients approach a straight line.

\section{Table 1. Percent Solute Removed and Retained as a Function of Volume-Equivalents During} Diafiltrationa

\begin{tabular}{|c|c|c|}
\hline$\underline{V}_{x} \underline{N}_{0}$ Retained & $\%$ Solute Removed & $\%$ Solute \\
\hline-1 & 63.2 & 36.8 \\
\hline 2 & 86.5 & 13.5 \\
\hline 3 & 95.0 & 5.0 \\
\hline 4 & 98.2 & 1.8 \\
\hline 5 & 99.3 & 0.7 \\
\hline 10 & $99.9+$ & $<0.1$ \\
\hline
\end{tabular}

$a^{a}=0.0$ with continuous water addition assumed

In the recovery of metal ions from electroplating rinse waters, both the concentration and diafiltration modes of operation are in effect. In a batch treatment of rinse waters, the polymer would be added to the rinse waters. Within a few minutes of mixing, the complexation of metal ions in solution would be complete and the volume of solution then reduced by operating in the concentration mode and the final metal ion concentration determined by Eq. (3). The metal ions are released from the polymer by some chemical process, possibly lowering the $\mathrm{pH}$. When the metal ions are no longer bound to the polymer, they freely pass through the membrane and are collected as permeate during diafiltration, while the regenerated polymer is retained for recycle.

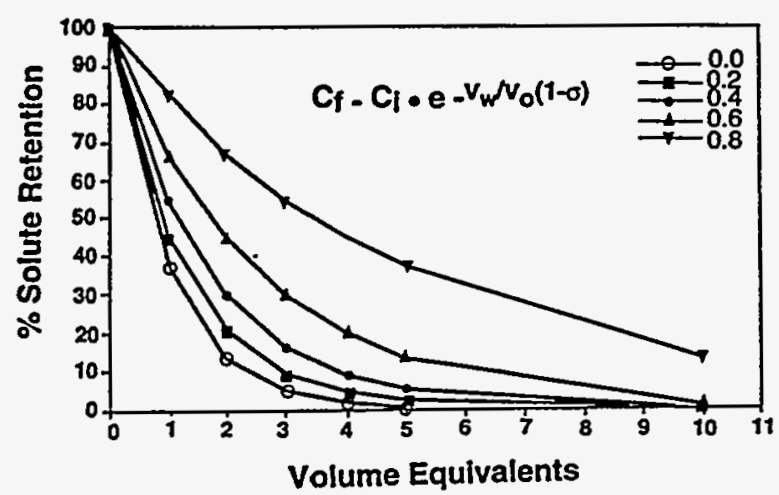

Fig. 4-Solute retained at various rejection coefficients during diafiltration.

When the ultrafiltration processes of concentration and diafiltration are combined, an effective method for the recovery, concentration, and purification of the metal ions in solution can be achieved. A number of industries successfully use ultrafiltration processes for various applications, including water purification, waste treatment, pharmaceuticals, life sciences, and the food and beverage industry.

\section{Evaluation of Polymer Filtration for Electroplating Applications}

New alloy electroplating baths are under development to replace cadmium baths. The zinc-nickel alloy bath has shown the most promise at this time. It was chosen for development of a metal-ion recovery system from rinse waters such that a near closed-loop system could be developed simultaneousiy with the bath development ancl testing. The composition of the new electroplating bath is shown in Table 2 .

Retention studies were performed on diluted electroplating bath solutions to evaluate the PF technologies effectiveness in retaining the plating metals in the presence of other bath constituents. BOE-NIZ was deliberately omitted from the test solutions since it was removed by carbon treatment prior to ultrafiltration in the demonstration (siee Demonstration at Boeing Electroplating Facility).

\section{Table 2. Composition of Simulated Ni-Zn Electroplalling Bath Solutionb}

\begin{tabular}{lrcr} 
Formula & MW & grams/iter & oz/gal \\
\cline { 2 - 2 } $2 \cdot 6 \mathrm{H}_{2} \mathrm{O}$ & 237.7 & 73.2 & 9.8 \\
$\mathrm{ZnO}$ & 81.4 & 11.2 & 1.5 \\
$\mathrm{NH}_{4} \mathrm{Cl}$ & 53.5 & 170.4 & 22.8 \\
$\mathrm{H}_{3} \mathrm{BO}_{4}$ & 61.8 & 20.4 & 2.7 \\
$\begin{array}{l}\mathrm{BOE}-\mathrm{NIZ} \\
\text { (porosity control) }\end{array}$ & & $50 \mathrm{~mL}$ &
\end{tabular}

${ }^{b}$ pH adjusted to 6.5

To simulate the electroplating rinse waters, the above solution was diluted $1: 100$, resulting in nickel and zinc metal ion concentrations in the range of $180 \mathrm{ppm}$ and $90 \mathrm{ppm}$, respectively. The general procedure for retention studies added excess polymer (Metal-Set-Z) to the simulated rinse waters. The solutions were adjusted to the desired $\mathrm{pH}$ values (1-7) and ultrafiltered through a flat membrane, using an Amicon stirred cell. The volumes of retentate and permeate were measured and both analyzed for nickel and zinc by inductively coupled plasma-atomic emission spectroscopy (ICP-AES) or ICP-mass spectrometry (ICP-MS). The detection limit for metal ions for these analytical techniques are 0.1 and $0.01 \mathrm{ppm}(\mu \mathrm{g} / \mathrm{mL})$, respectively.

The results for the retention of nickel and zinc by Metal-Set- $Z$ are shown in Fig. 5 . The Metal-Set- $Z$ has good retention for both metals at pH 5 and above. Below pH 5, the polymer begins to release the metals, and by $\mathrm{pH} 3$, most metals are free in solution. The observation that there is very little change in the percent metal retained below $\mathrm{pH} 3$ suggests that there is still some polymer/metal-ion interaction at low $\mathrm{pH}$ (i.e. $\sigma \neq 0$ for the metal ions).

$$
\mathrm{P}+\mathrm{M}^{\mathrm{n}+} \rightleftharpoons-\mathrm{PM}^{\mathrm{n}+}
$$

\footnotetext{
- Metal-Sel- $Z$ is a proprietary polymer developed for metal removal from waste streams and is now available from Micro-Set, Landisville, NJ.
} 
While these single-contact results indicate a significant percentage of the metal ions remain in the retentate due to this polymer/metal-ion interaction, during a diafiltration process the metal ions are constantly being removed from the retentate side of the membrane. Therefore, the above equilibrium is continuously being shifted towards the left, freeing more metal ions and allowing them to permeate the membrane. Within experimental error, there were no differences in the selectivity of Metal-Set-Z for one metal over the other in these studies.

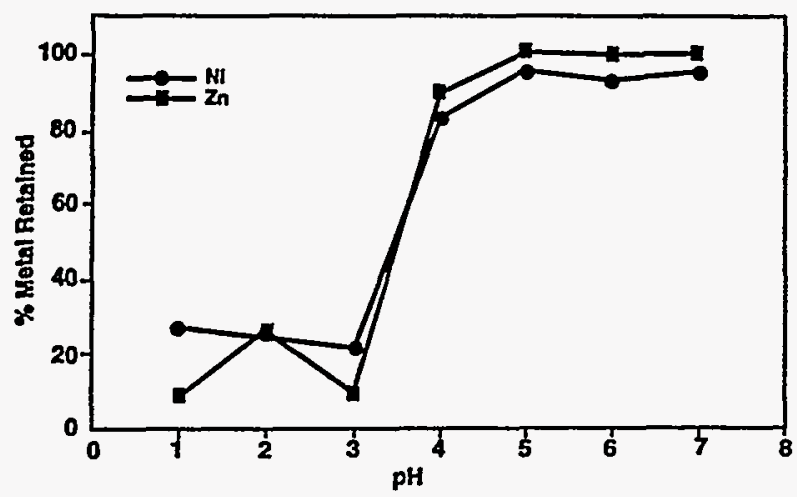

Fig. 5-Retention of nickel and zinc by Metal-Set-Z.

\section{Regeneration Studies}

The purpose of the regeneration studies was to investigate the ability of Metal-Set- $Z$ to complete a full cycle of metal-ion retention/concentration, metal-ion recovery by diafiltration, and polymer reloading using the simulated rinse waters. In a general procedure, dilute electroplating bath solutions $(50 \mathrm{~mL})$ were treated with excess Metal-Set- $Z$ at $\mathrm{pH}$.6. These solutions were concentrated to $10 \mathrm{~mL}$ using a stirred cell with a flat membrane. The metal ions were released from the polymer by adjusting the $\mathrm{pH}$ with hydrochloric acid and were collected by diafiltration. This procedure was repeated an additional 2 times after raising the $\mathrm{pH}$ of the polymer retentate to 6 with ammonium hydroxide.

For polymer regeneration studies, the initial concentrations of nickel and zinc in the solution at pH 6 were $45 \mathrm{ppm}$ and $24 \mathrm{ppm}$, respectively, as determined by ICP-AES. During the first concentration to $10 \mathrm{~mL}$, retention of the nickel and zinc was $>99 \%$ with no detectable metals in the permeate.

After adjusting the $\mathrm{pH}$ to 2, the solution was diafiltered and 6 volume-equivalents collected. Some weak polymer/metal-ion interactions are still present at $\mathrm{pH} 2$ because both of the curves fall above the theoretical values calculated from $\mathrm{Eq}$. (5).

The second and third regeneration results were similar to those of the first. The percent of zinc and nickel ions retained after each volume-equivalent is shown in Fig. 6 . In both concentration steps no metal ions were detected in the permeate, indicating $>99 \%$ retention. The 2 diafiltrations followed a similar trend with all curves falling slightly above the theoretical val-

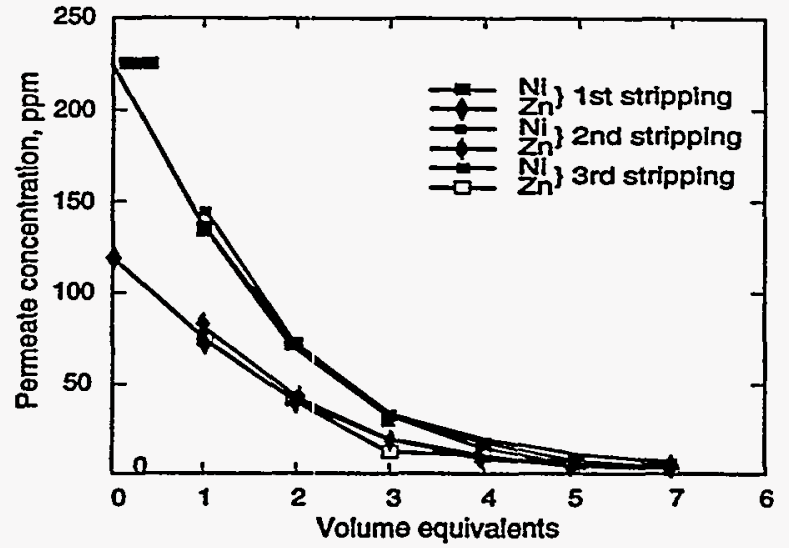

Fig. 6-The multiple diafiltrations with Metal-Set-Z for zinc and nickel.

ues for $\sigma=0$. The conclusions of the study indicate that Metal-Set-Z can successfully retain electroplating bath metals from dilute solutions, that the metals can be concentrated, recovered, and the polymer recycled without the loss of performance.

\section{Metal-Ion Retention Using Ultrafiltration Membrane Cartridges}

An actual process could not use dead-end ultrafiltration because the flux or flow rates would be too slow for a practical process. Thus, further studies with a simulated electroplating rinse water $(5.5 \mathrm{~L})$ solution using a tangential-flow ultrafiltration cartridge were performed to determine the effectiveness of Metal-Set$Z$ in retaining, concentrating, and recovering metal ions from electroplating rinse waters and to evaluate flux properties of the system. The initial concentrations of nickel and zinc in the solution as determined by ICPMS were $165 \mathrm{ppm}$ and $91.4 \mathrm{ppm}$, respectively. The boron concentration from boric acid was $31.7 \mathrm{ppm}$. The $\mathrm{pH}$ of the solution was adjusted to 6.3 by the addition of concentrated hydrochloric acid.

Conditions for the process involved the use of an ultrafiltration cartridge (1.5 sq. $\mathrm{ft}, 0.14 \mathrm{sq} \mathrm{m}$ surface area). Recirculation rales of solution inside the membrane ( $-4 \mathrm{~L} / \mathrm{min})$ were maintained using a peristaltic pump. The operating back-pressure was $15 \mathrm{psig}$ (pure water flux at this back pressure was $147 \mathrm{~mL} / \mathrm{min}$ ). The initial concentration of Metal-Set- $Z$ was $0.12 \%$ by weight. Based on $0.25 \mathrm{~g}$ metal/g polymer loading capacity for Metal-Set-Z, quantitative zinc and nickel metal-ion retention would utilize approximately $70 \%$ of Metal-Set-Z's capacity. The final volume of the solution after the concentration step was $\sim 350 \mathrm{~mL}$, or a concentration factor of about 15-fold. Permeate rates, taken every $1000 \mathrm{~mL}$, are displayed in Fig. 7 and indicate an interesting result. After the first $3000 \mathrm{~mL}$ of permeate was collected, there was no decrease in the flux rates, which were $65 \%$ that of pure water. This lack of decrease occurred despite an increase in Metal-SetZ's concentration from $0.12 \%$ to $0.21 \%$. Only after 
$4000 \mathrm{~mL}$ of permeate was collected did the flux rates begin to drop. During this volume reduction, the average concentration of metal ions in the permeate was $-1 \mathrm{ppm}$ for nickel and $2.3 \mathrm{ppm}$ for zinc, indicating reasonable metal-ion retention by Metal-Set-Z.

After the solution was concentrated by a factor of 15 , the metals were released from the polymer by the addition of concentrated hydrochloric acid to a final $\mathrm{pH}$ of 2.0. At this point, the initial permeate from the diafiltration process was estimated to have a metal ion concentration approximately 10 times that of the initial metal ion concentrations. The results from the ICP-MS are in close agreement, showing $1617 \mathrm{ppm}$ nickel and $1009 \mathrm{ppm}$ zinc in the first volume-equivalent of permeate. The concentrations of nickel and zinc in successive permeate fractions followed the expected decrease.

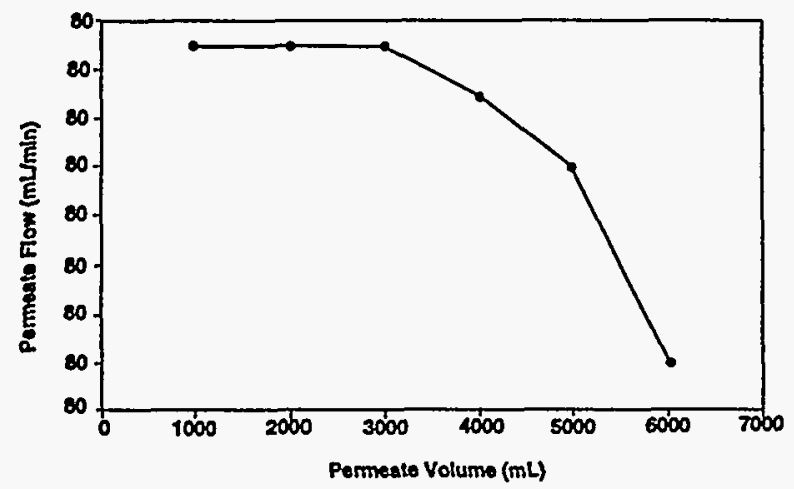

Fig. 7-The effect of the concentration process on permeate flux.

It was determined that boron did not interfere with zinc and nickel binding. With the possibility of electrostatic bonding between boric acid and the polymer, boric acid might also be concentrated to a certain degree. The initial concentration of boron in the solution before volume reduction was $31.7 \mathrm{ppm}$. The concentration in the permeate during the volume reduction was $\sim 34 \mathrm{ppm}$; the concentration of boron during the diafiltration process after acidification was $31.5 \mathrm{ppm}$ in the first permeate fraction with each subsequent volume-equivalent showing a decrease in concentration. This is strong evidence that there is little, if any, interaction between the polymer and the boric acid, and therefore boric acid should not interfere with the polymer/metal-ion binding.

A few additional tests were performed to determine if any polymer degradation occurred (cleavage of polymer could result in loss of polymer through the ultrafiltration membrane). During 6 hours of continuous processing of a $1 \%$ Metal-Set-Z solution (with both the retentate and the permeate recirculated back into the feed reservoir), no increase of polymer loss was observed through an ultrafiltration cartridge. The temperature of the recycling solution increased from 24 to $40.5^{\circ} \mathrm{C}$ during the continuous cycling of the polymer through the pump (magnetic drive) and system (see demonstration details). Permeate samples taken every 2 hours over the 6-hour period were analyzed for polymer breakthrough using a spectroscopic detection method that was sensitive to $1 \mathrm{ppm}$ of polymer.

\section{Metal-Ion Selectivity Studies}

Metal-ion impurities often enter an electroplating bath from reagents, the materials being plated, and/or the electroplating equipment. Iron and copper are 2 metals that often contaminate baths. For an electroplating metal-ion recycle system to function properly it must selectively recover nickel and zinc and separate them from metal impurities such that the impurities are not retumed to the bath. To test the selectivity of MetalSet-ZM ${ }^{*}$, a solution of the electroplating rinse water (40 gallons) prepared according to Table 1 and diluted approximately 1:100 was spiked with low levels ( 5 $\mathrm{ppm}$ ) of copper and iron chloride and adjusted to $\mathrm{pH}$ 7.0. The polymer had an initial concentration of $0.15 \%$ by weight. Based on results obtained from previous loading capacity studies, calculations indicated that the retention of all metal ions in solution would give an $80 \%$ loading of the polymer. The analysis of the initial feed solution by ICP-MS is shown in the top of Table 3.

The concentration stage of the test, the permeate flow rate as well as the total volume of permeate collected as a function of time, is shown in Fig. 8. The total time to process the forty gallons of solution was approximately one hour. The permeate collected during the concentration stage was analyzed for metal-ion content and gave a nickel and zinc concentration of $1.94 \mathrm{ppm}$ and $1.35 \mathrm{ppm}$, respectively.

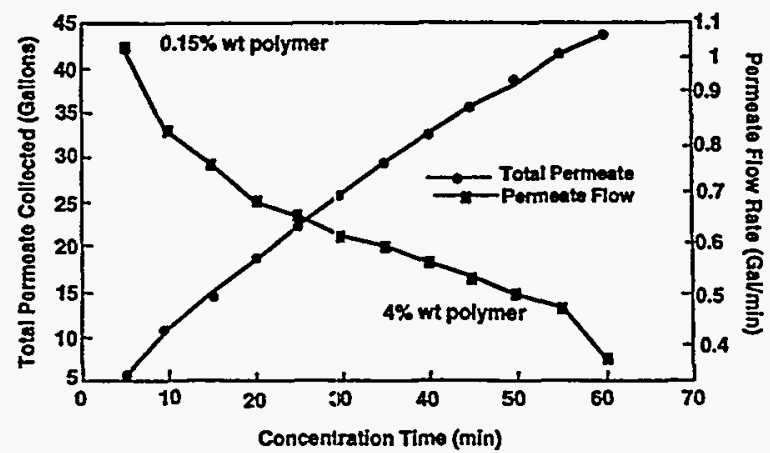

Fig. 8-Permeate flow and rate of collection during the 40 gallon concentration.

Once the solution was concentrated to approximately 1.5 gallons, the $\mathrm{pH}$ of the solution was lowered to 3.5 with hydrochloric acid and diafiltered to release the metal ions. Five volume-equivalents were collected and each fraction analyzed for metal ion-concentration (Table 3). It is clear from the results that pH 3.5 is not the optimum $\mathrm{pH}$ for zinc and nickel ion release. This polymer solution appeared to have a slightly greater retention for nickel than for zinc, however, after five

\footnotetext{
"Metal-Set-ZM is a modified formulation of Metal-Set-Z for improved performance. Available from Micro-Set, Landisville, N.J.
} 
volume-equivalents, significant amounts of both nickel and zinc still remained in the retentate. This is contrary to theoretical models which predict that greater than $95 \%$ of the metal ions should have passed through the membrane after five volume-equivalents if no polymer/metal-ion interactions existed. Analysis results for other metal ions indicated that at $\mathrm{pH} 3.5$ copper and iron were still substantially retained. The $\mathrm{pH}$ of the retentate was then lowered a second time to 3.0. The first volume-equivalent of permeate during the second diafiltration process gave nickel and zinc ion concentrations of $473 \mathrm{ppm}$ and $153 \mathrm{ppm}$, respectively. These results confirmed that significant polymer/metal-ion interactions existed at $\mathrm{pH} 3.5$. The $\mathrm{pH}$ of the retentate was lowered a third time to $\mathrm{pH} 1$. The nickel concentration in the permeate was $80.6 \mathrm{ppm}$ in the first volume-equivalent and down to $22.5 \mathrm{ppm}$ after the third volume-equivalent.

Analysis of the retentate after the diafiltration process indicates that more of the nickel $(42 \mathrm{ppm})$ was retained than the zinc $(1.9 \mathrm{ppm})$, which suggests that there is a slightly stronger interaction between the Metal-Set-ZM with nickel than with zinc. Copper and iron were found to be significantly concentrated in the retentate at $17.5 \mathrm{ppm}$ and $26.3 \mathrm{ppm}$, respectively. While there was no indication that iron was being released from the polymer at low $\mathrm{pH}$, the copper concentration in the first volume-equivalent collected at $\mathrm{pH}=1$ was $14.0 \mathrm{ppm}$.

Several conclusions can be drawn from the results of the experiment. All the metal ions were removed from the rinse water stream and concentrated in the first step, indicating that the process can easily meet EPA discharge limits. The optimum release of the nickel and zinc occurred at or slightly below a pH of 3.0. Diafiltration at this $\mathrm{pH}$ will reduce the number of volume-equivalents needed to recover $>95 \%$ of the nickel and zinc in the concentrated rinse waters to about 3. Copper and iron were retained and separated from zinc and nickel at $\mathrm{pH} 3$.

\section{Demonstration at Boeing Electroplating Facility}

The focus of the demonstration at the Boeing Facility in Seattle was the treatment of 100 gallons of electroplating rinse waters for the nickel-zinc alloy baths. Objectives for success were set:

(1) Nickel and zinc had to be removed from the process rinse water to less than $1 \mathrm{ppm}$, meeting EPA discharge levels.

(2) The plating metals had to be recovered in a concentrated, contaminant-free form.

(3) The recovered metals had to be retumed to the original plating baths without adverse effects on the plating process (the polymer filtration process would be performed within the chemistry of the nickel-zinc plating bath).

(4) The polymer solution would be reused for further metal-ion recovery.

(5) The process had to be performed within an 8-hour period.

\section{Ultrafiltration Unit}

The demonstration at Boeing required building a pilot-scale ultrafiltration unit large enough to process 100 gallons of the plating rinse waters within an 8-hour period. Certain commercially available ultrafiltration units were capable of accomplishing this task; however, these units were expensive. The goal in building the ultrafiltration unit was to construct a lightweight, inert, mobile, and relatively inexpensive system which could easily fit between the rows of electroplating baths at Boeing ( $(3 \mathrm{ft}$.) A picture of the system is shown in Fig. 9. Unlike the commercial systems, this system used PVC plumbing to reduce the cost, weight, and contamination problems of stainless steel. The completed unit was mounted on a cart for mobility and weighed less than 100 pounds. The major cost for the unit came from the 2 ultrafiltration cartridges, which had a total of 72 sq. ft. of membrane surface area.

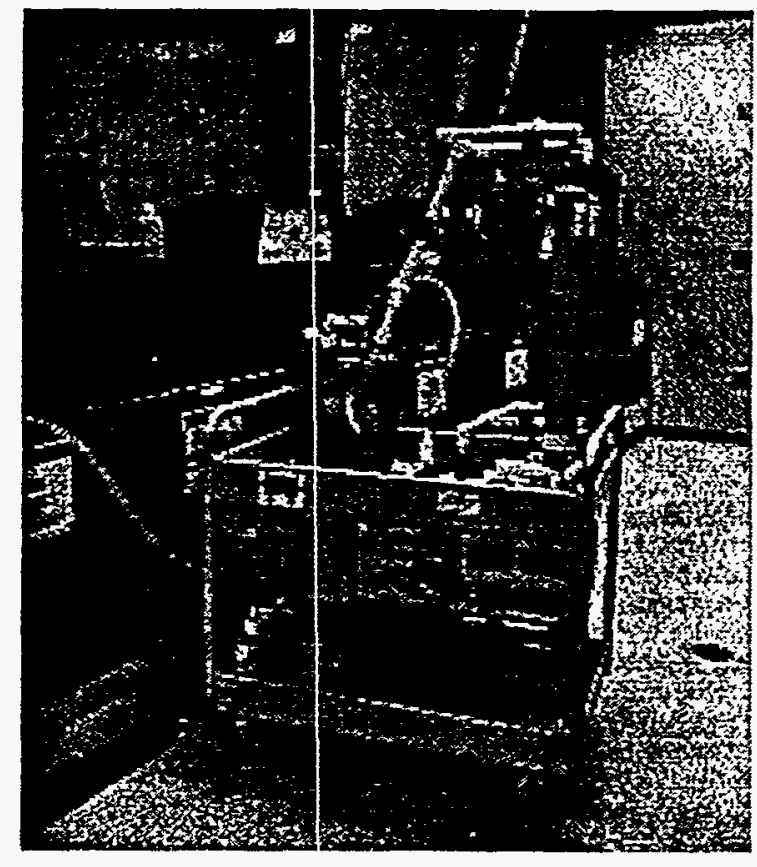

Fig. 9-Small, portable, and light polymer filtration unit.

\section{Procedure}

A schematic of the polymer filtration process used at Boeing is illustrated in Fig. 10. For the demonstration, one liter of the zinc and nickel alloy electroplating bath solution with nickel and zinc concentrations of approximately $17,800 \mathrm{ppm}$ and $8,000 \mathrm{ppm}$, respectively (based on analyses performed at Boeing's analytical laboratory) was added to the 100 gallons of tank rinse water to simulate drag-out. The diluted solution was mixed thoroughly using compressed air, resulting in a cloudy blue-green solution at $\mathrm{pH}$ 7.7. The cloudiness was the result of a metal hydroxide precipitation of zinc. One-half of this solution was transferred to a 55gallon plastic drum. The $\mathrm{pH}$ was adjusted to 7.3 using 


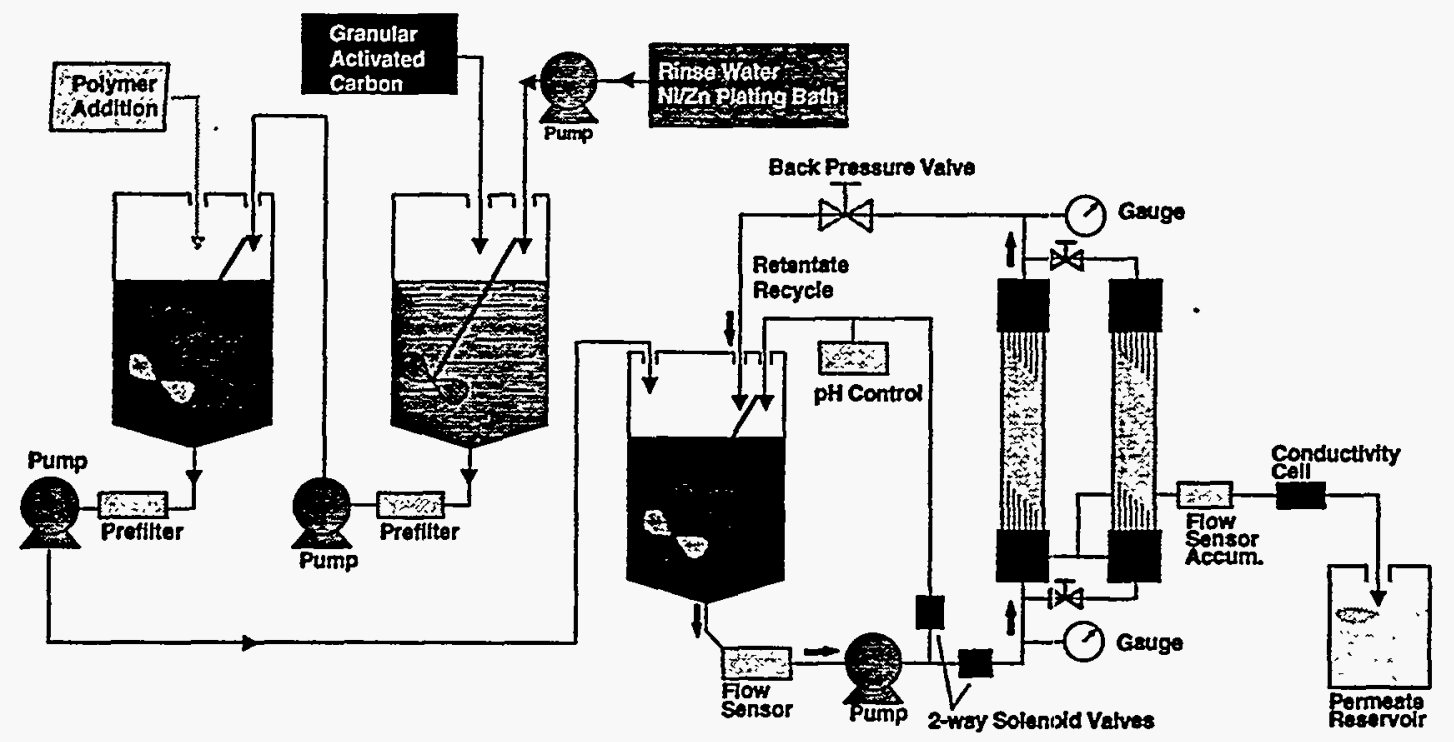

Fig. 10. Schematic of polymer filtration process using metal-binding polymers.

concentrated hydrochloric acid $(12 \mathrm{~mL})$, redissolving the suspended solids and clearing the solution.

Carbon ( 2 pounds) was added to the 50 gallons of solution to remove organics, including the BOE-NIZ, which could potentially foul the ultrafiltration membrane and to reduce foaming. After stirring for $20 \mathrm{~min}$ utes, the carbon was allowed to settle and the solution was monitored for the absence of surfactant*. It was then pumped through a 5-micron course filter into a second 55-gallon plastic drum. Metal-Set-ZM (165 g) was added to the drum and the solution was stirred for 5 minutes.

The solution was concentrated to approximately 1.5 gallons using the ultrafiltration process. A pH of 7.0-7.1 was maintained in the feed reservoir during the concentration phase by using the $\mathrm{pH}$ controller to automatically add small volumes of a $15 \%$ hydrochloric acid or ammonium hydroxide solution when $\mathrm{pH}$ adjust-

Table 3. Nickel and Zinc Concentrations in Various Samples

\begin{tabular}{llllll} 
Sample & $\mathrm{Ni}$ & $\mathrm{Zn}$ & $\mathrm{Cu}$ & $\mathrm{Fe}$ (opm) \\
\hline & & & & \\
Initial Conc. pH 7.0 & 126 & 69.8 & 2.35 & 3.78 \\
Permeate from Conc. & 1.94 & 1.35 & 0.02 & 0.25 \\
Vol. Eq. 1-pH 3.5 & 533 & 699 & 0.79 & 1.52 \\
Vol. Eq. 2-pH 3.5 & 422 & 377 & 0.44 & 1.37 \\
Vol. Eq. 3-pH 3.5 & 398 & 234 & 0.24 & 1.25 \\
Vol. Eq. 4-pH 3.5 & 331 & 156 & 0.15 & 1.25 \\
Vol. Eq. 5-pH 3.5 & 325 & 153 & 0.10 & 0.52 \\
Vol. Eq. 1-pH 3.0 & 473 & 30 & 2.84 & 1.24 \\
Vol. Eq. 4-pH 3.0 & 44.8 & $<4$ & 1.41 & 0.60 \\
Vol. Eq. 1-pH 1.0 & 80.6 & $<4$ & 14.1 & 1.76 \\
Vol. Eq. 3-pH 1.0 & 22.5 & 2.97 & 2.33 & 0.74 \\
Retentate & 42.1 & 1.94 & 17.5 & 26.3
\end{tabular}

ment was necessary. Permeate samples were taken periodically at $5,20,35$, and 50 gallons of permeate volume processed. The above process was repeated with the second 50 gallons of rinse water solution. After carbon filtration, the 1.5 gallons of concentrated polymer/nickel-zinc retentate from the first 50 gallons was used to treat the secorid 50 gallons, since only $30 \%$ of the polymer's full capacity had been reached. The second concentration process was run at the lower $\mathrm{pH}$ of 6.0 , with permeate samples again taken for every 15 gallons of permeate generated.

Diafiltration was performed on the concentrated 1.5 gallon solution by first lowering the $\mathrm{pH}$ of the retentate solution to $\mathrm{pH} 2.9$ using $15 \%$ hydrochloric acid. Deionized water was pumped into the feed reservoir at the same rate as the permeate was generated. Permeate samples were taken approximately every one-half volume-equivalents, or 0.8 gallons, for nickel and zinc analysis.

A second polymer filtration process was performed on a third 50 gallons of plating rinse water. For this solution, $250 \mathrm{~mL}$ of the plating bath and permeate volumes 4 and 5 from the first 100 gallon test were added to the 50 gallons of water. The solution was treated with 1 pound of carbon, filtered, and the $\mathrm{pH}$ raised from 5.5 to 7.0 using ammonium hydroxide. After filtering through a course filter and transferring to the second holding tank, the polymer used in the first polymer filtration was added and the solution processed under conditions similar to those described above. The $\mathrm{pH}$ for the process was held at 7.0. Diafiltration of the concentrated 1.5 gallons of solution was again performed at a pH of 2.9 with samples being collected at 0.5 volume-equivalents for metal analysis.

A complete summary of the concentration and diafiltration processes including the results from the analysis for nickel and zinc are given in Tables 5-7.

\footnotetext{
"An in-line surfactant monitor is not commercially available at this time. A new sensor was developed for these tests (patent pending). We intend to have an in-line surfactant monitor available in the near future.
} 
Prior to starting the metal recovery experiments test panels $\left(4^{n} \times 6^{n}\right)$ of 4131 alloy steel were plated to determine the baseline behavior of the bath. Further panels were plated after recovered metal-ion concentrate was added to the bath. All panels were submitted to salt-spray corrosion testing.

Results and Discussion of Boeing Demonstration

The 100 gallons of rinse water was analyzed on site for nickel using the Hach test kit and was determined to be $44 \mathrm{ppm}$ nickel. This amount was in close agreement with the theoretical value of $47 \mathrm{ppm}$ $(17,800 \mathrm{ppm} / 378 \mathrm{~L}=47 \mathrm{ppm})$ determined by Boeing for the nickel concentration in the actual plating bath. Subsequent analysis of the rinse water solution at Los Alamos National Laboratory by ICP-MS gave the nickel and zinc concentrations at $43 \mathrm{ppm}$ and $12 \mathrm{ppm}$, respectively. The lower than expected zinc concentration may have been a result of some zinc lost as a hydroxide precipitate during the original dilution step.

During the concentration process for the first 50 gallons, the $\mathrm{pH}$ of the feed solution was maintained at 7.0. On-site analysis of the permeate for nickel using the Hach kit indicated the concentration to be less than $1 \mathrm{ppm}$. The subsequent analysis of samples taken during the process by ICP-MS gave concentration values of $<0.05 \mathrm{ppm}$ for nickel and $0.097 \mathrm{ppm}$ for zinc. These are well below the discharge limits for both metals. The second 50 gallons was processed at the lower $\mathrm{pH}$ of 6.0. At this $\mathrm{pH}$, nickel was not efficiently retained, with $10-15 \mathrm{ppm}$ coming through the membrane with the permeate. Zinc, at $<0.05 \mathrm{ppm}$, was still well below discharge levels. These results indicate the importance of performing the concentration stage at the optimum $\mathrm{pH}$ to insure all metals are retained during the process. The time for concentrating 100 gallons to 1.5 gallons was 2 hours with a back pressure of $\sim 3$ psig.

After the volume reduction of 100 gallons to approximately 1.5 gallons, the $\mathrm{pH}$ of the solution was adjusted to 2.9 by the addition of dilute hydrochloric acid. Deionized water was introduced during the diafiltration process and volume-equivalents of permeate were taken on 0.5 intervals with 2.5 volume-equivalents total collected. The approximate concentration of nickel and zinc in the 2.5 volume-equivalents $(3.75 \mathrm{gal}-$ lons) collected was $946 \mathrm{ppm}$ and $431 \mathrm{ppm}$, respectively. The retentate of 1.5 gallons contained nickel and zinc at $166 \mathrm{ppm}$ and $72 \mathrm{ppm}$ respectively. The second diafiltration process for the $\mathbf{5 0}$ gallons of rinse water concentrated to approximately $\mathbf{1 . 5}$ gallons was performed under similar conditions. The final concentration of nickel and zinc in 2.5 volume-equivalents was $449 \mathrm{ppm}$ and $191 \mathrm{ppm}$, respectively. Total time for each diafiltration was approximately 15 minutes.

Corrosion protection is a requirement for zincnickel coatings. The plating must pass 96 hours of neutral salt-spray testing per ASTM B117, "Salt-Spray (Fog) Testing," with neither white corrosion products of zinc nor base metal corrosion products visible to the unaided eye. For our demonstration, corrosion
Table 4. Results of the Concentration of the First 100 Gallons (Boeing Demonstration)

\begin{tabular}{|c|c|c|c|c|c|}
\hline $\begin{array}{l}\text { Perm. } \\
\text { Vol } \\
\text { Gal. }\end{array}$ & $\begin{array}{l}\text { Total } \\
\text { Time } \\
\text { Min }\end{array}$ & $\begin{array}{l}\text { Back } \\
\text { Press. } \\
\text { PSIG }\end{array}$ & $\begin{array}{l}\text { Perm. } \\
\text { Flow } \\
\text { Gal.Min }\end{array}$ & \multicolumn{2}{|c|}{$\begin{array}{l}\text { LANL analysis } \\
\text { [Ni]pom [Zn]ppm }\end{array}$} \\
\hline 0 & 0 & & & & \\
\hline $\begin{array}{c}5^{a} \\
10 \\
15\end{array}$ & $\begin{array}{l}5: 44 \\
12: 00 \\
18: 09\end{array}$ & $\begin{array}{l}2 \\
3 \\
3\end{array}$ & $\begin{array}{l}0.69 \\
0.82 \\
0.78\end{array}$ & $<0.05$ & 0.097 \\
\hline $\begin{array}{l}20^{a} \\
25 \\
30\end{array}$ & $\begin{array}{l}24: 43 \\
31: 18 \\
38: 16\end{array}$ & $\begin{array}{l}2.8 \\
2.8 \\
2.8\end{array}$ & $\begin{array}{l}0.74 \\
0.74 \\
0.72\end{array}$ & & \\
\hline $\begin{array}{l}35^{a} \\
40\end{array}$ & $\begin{array}{l}45: 20 \\
52: 48\end{array}$ & $\begin{array}{l}2.7 \\
2.7\end{array}$ & $\begin{array}{l}0.68 \\
0.64\end{array}$ & & \\
\hline $45^{b}$ & $1: 00: 50$ & 2.6 & 0.51 & & \\
\hline $50^{a}$ & $4: 22$ & 2.9 & 0.86 & $\begin{array}{l}15.0 \\
d(10.3)\end{array}$ & $\begin{array}{l}<0.05 \\
d(<0.1)\end{array}$ \\
\hline $\begin{array}{l}55 \\
60\end{array}$ & $\begin{array}{l}10: 00 \\
15: 50\end{array}$ & $\begin{array}{l}3 \\
3\end{array}$ & $\begin{array}{l}0.86 \\
0.84\end{array}$ & & \\
\hline $\begin{array}{l}65^{a} \\
70 \\
75\end{array}$ & $\begin{array}{l}22: 00 \\
28: 07 \\
34: 29\end{array}$ & $\begin{array}{l}2.9 \\
2.9 \\
2.8\end{array}$ & $\begin{array}{l}0.8 \\
0.79 \\
0.77\end{array}$ & & \\
\hline $\begin{array}{l}80^{a} \\
85 \\
90\end{array}$ & $\begin{array}{l}40: 58 \\
47: 46 \\
54: 50\end{array}$ & $\begin{array}{l}2.7 \\
2.7 \\
2.6\end{array}$ & $\begin{array}{l}0.69 \\
0.72 \\
0.69\end{array}$ & & \\
\hline $95^{a}$ & 1:02:00 & 2.5 & 0.63 & 13.7 & 0.13 \\
\hline
\end{tabular}

apermeate samples taken.

bTemperature was $25-28^{\circ} \mathrm{C}$ and the $\mathrm{pH}$ was 7.0-7.1

CTemperature was $22^{\circ} \mathrm{C}$ and the $\mathrm{pH}$ was 5.9-6.4

Boeing Analysis by $A A$

eg6.88 total gallons processed

Table 5. Results of the Diafiltration of the First 100 Gallons (Boeing Demonstration)

\begin{tabular}{|c|c|c|c|c|}
\hline \multirow{2}{*}{$\begin{array}{l}\text { Volume. } \\
\text { Eq } \\
\text { Gal. }\end{array}$} & \multirow{2}{*}{$\begin{array}{l}\text { Back } \\
\text { Press. } \\
\text { PSIG }\end{array}$} & \multirow{2}{*}{$\begin{array}{l}\text { Per. } \\
\text { Flow } \\
\text { Gal/Min }\end{array}$} & \multicolumn{2}{|c|}{ LANL Analysis } \\
\hline & & & [Ni] nom & $\mathrm{ZnI}$ lom \\
\hline 0.5 & 2.3 & 0.19 & $\begin{array}{l}1422 \\
b(1.3)\end{array}$ & $\begin{array}{l}674 \\
\mathrm{~b}(0.6)\end{array}$ \\
\hline 1 & 2.5 & 0.17 & 1451 & 656 \\
\hline 1.5 & 2.6 & 0.15 & $\begin{array}{l}934 \\
b(0.8)\end{array}$ & $\begin{array}{l}413 \\
\mathrm{~b}(0.4)\end{array}$ \\
\hline${ }^{2} 2.50^{*}$ & $\begin{array}{l}2.6 \\
2.6\end{array}$ & $\begin{array}{l}0.15 \\
0.14\end{array}$ & $\begin{array}{l}578 \\
344 \\
166\end{array}$ & $\begin{array}{c}255 \\
156 \\
72\end{array}$ \\
\hline
\end{tabular}

a Total volume processed yras approximately 3.75 gallons (14.2 Liters) in 13 minutes, $\mathrm{pH}$ was 2.8-2.9, and temperature was 25$26^{\circ} \mathrm{C}$

bBoeing Analysis by AA in $g / L$.

"Hach Nickel Kit available from Hach Co., P.O. Box 389, Loveland, CO. 
Table 6. Results of the Concentration of the Second 50 Gallons (Boeing Demonstration)

\begin{tabular}{|c|c|c|c|c|c|}
\hline Perm Vol. & Total & Back & Perm. & LANL A & alysis \\
\hline Gal. & Min & PSIG & Gal./Min & INII opm & Znlopm \\
\hline 0 & 0 & & & & \\
\hline $\begin{array}{c}5^{a} \\
10 \\
15\end{array}$ & $\begin{array}{l}5: 44 \\
11: 00 \\
16: 27\end{array}$ & $\begin{array}{l}3 \\
3.1 \\
3.2\end{array}$ & $\begin{array}{l}0.87 \\
0.91 \\
0.94\end{array}$ & 0.197 & 0.035 \\
\hline $\begin{array}{l}20^{a} \\
25 \\
30\end{array}$ & $\begin{array}{l}21: 55 \\
27: 30 \\
33: 34\end{array}$ & $\begin{array}{l}3.2 \\
3.2 \\
3.1\end{array}$ & $\begin{array}{l}0.9 \\
0.85 \\
0.82\end{array}$ & & \\
\hline $\begin{array}{l}35^{\circ} \\
40\end{array}$ & $\begin{array}{l}39: 34 \\
48: 10\end{array}$ & $\begin{array}{l}3.1 \\
1.6\end{array}$ & $\begin{array}{l}0.79 \\
0.54\end{array}$ & 0.085 & 0.014 \\
\hline 45 & $57: 32$ & 1.5 & 0.52 & ${ }^{c}(0.4)$ & ${ }^{c}(<0.1)$ \\
\hline $47.6^{d}$ & $1: 01: 24$ & 1.5 & 0.51 & & \\
\hline
\end{tabular}

Note: Back pressure on this run was not held constant

apermeate samples taken.

bTemperature was $21-22^{\circ} \mathrm{C}$ and the $\mathrm{pH}$ was 7.0-7.2

CBoeing Analysis by AA in ppm.

Total volume processed

Table 7. Results of the Diafiltration of the Second 50 Gallons (Boeing Demonstration)

\begin{tabular}{|c|c|c|c|}
\hline $\begin{array}{l}\text { Volume } \\
\text { Eq. } \\
\text { Gal. }\end{array}$ & $\begin{array}{l}\text { Back } \\
\text { Pres. } \\
\text { PSIG }\end{array}$ & \multicolumn{2}{|c|}{$\begin{array}{l}\text { LANL Analysis } \\
\text { [Ni] ppm [Zn] ppm }\end{array}$} \\
\hline 0.5 & 2.2 & $\begin{array}{l}654 \\
b(0.6)\end{array}$ & $\begin{array}{l}251 \\
b_{(0.3)}\end{array}$ \\
\hline $\begin{array}{l}1 \\
1.5 \\
2\end{array}$ & $\begin{array}{l}2.6 \\
2.6 \\
2.6\end{array}$ & $\begin{array}{l}767 \\
428 \\
253\end{array}$ & $\begin{array}{l}337 \\
189 \\
113\end{array}$ \\
\hline $\begin{array}{l}2.50^{\mathrm{a}} \\
\text { Retentate }\end{array}$ & 2.6 & $\begin{array}{l}138 \\
53\end{array}$ & $\begin{array}{l}61 \\
16\end{array}$ \\
\hline \multicolumn{4}{|c|}{$\begin{array}{l}\text { Total volume processed was approximately } 3.75 \text { gallons }(14.2 \\
\text { Liters) in } 15 \text { minutes. The temperature was } 27-29^{\circ} \mathrm{C} \text {, and } \mathrm{pH} \\
\text { was } 2.8 \text { at an average flow rate of } 0.17 \mathrm{gal} / \mathrm{min} \text {. } \\
\text { b Boeing Analysis by.AA in } \mathrm{g} / \mathrm{L} \text {. }\end{array}$} \\
\hline
\end{tabular}

protection was used as a benchmark for success. If the salt spray results were positive, we assumed proper maintenance of the electroplating bath using recycled metals. Six $4^{\prime \prime} \times 6^{n} 4130$ alloy steel panels were zincnickel plated and chromate-conversion coated (per BAC 5637, Type II, Class 1) to an approximate thickness of $0.0005^{n}$ as control specimens. Two more sets of panels were plated following each addition of recovered metal solution. All three sets were then placed into salt-spray testing (ASTM B117) for 96 hours. Upon removal, no corrosion products were observed on any of the panels. From these results it was concluded that the use of recovered zinc-nickel from the polymer filtration process was not deleterious to the process and that our overall objective had been accomplished.

\section{Summary of Boeing Demonstration}

Based on the objectives set for a successful demonstration, the results indicate a very successful demonstration with all goals being met. The nickel and zinc were retained and concentrated from 100 gallons of electroplating rinse waters to 1.5 gallons, a volume concentration factor of 67 , and the permeate met discharge limits. The metals from this concentrate were successfully recovered from the polymer in a concentrated form (approximately 22-fold concentration factor) and returned to the original plating bath with subsequent electroplatings indicating no adverse effects on the quality of the plating. The regenerated polymer was successfully recycled to treat another 50 gallons of electroplating rinse waters. The entire process was performed within a 4-5 hour period, well below the allotted 8 hours. Finally, the process was conducted within the chemistry of the actual electroplating baths as only ammonium hydroxide and hydrochloric acid were used. No additional chemicals which would be incompatible with the electroplating bath solutions were introduced into the polymer filtration process.

\section{Conclusion}

Polymer Filtration (PF) was evaluated for the recovery of electroplating metal ions (zinc and nickel) from rinse waters. Polymer Filtration combines the use of water-soluble metal-binding polymers and ultrafiltration to concentrate metal ions from dilute rinse water solutions. The metal ions are retained by the polymers; the smaller, unbound species freely pass through the ultrafiltration membrane. By using this process the ultrafiltered permeate more than meets EPA discharge limits. The metal ions are recovered from the concentrated polymer solution by $\mathrm{pH}$ adjustment using diafiltration and can be recycled to the original electroplating baths with no deleterious effects on the test panels. Metal-ion recovery is accomplished without producing any sludge.

\section{Acknowledgements}

The authors would like to acknowledge the Department of Energy, Office of Industrial Technology, Industrial Waste Reduction Program for support of this development effort. We want to particularly thank Earl C. Groshart (Technical Fellow; Materials, Processing, and Physics) and Mary J. Nelson both of Boeing Defense and Space Group, Seattle, Washington, for their help, guidance and support; and for the use of their facilities for the demonstration phase of this project. We wish to thank Dr. Jose Olivares for the ICP analyses. This work was preformed under a contract with the Department of Energy. Contract \#W-7405ENG-36. 


\section{References}

1 Cherry, K.F., Plating Waste Treatment, Ann Arbor

Sciences Publishers Inc., Ann Arbor Michigan, (1982)

2 Strathman, H. Sep. Sci. Tech., 15(4), 1135-1152 (1980)

3 Geckler, K. E., Bayer, E., Spivakov, B. YA.,Shkinev, V.

M., Vorobeva, G. A., Anal. Chim. Acta, 285-292. (1986)

4Nguyen, Q. T., Aptel, P., Neel, J., J. Mem. Sci, 71-72.

(1980)

${ }^{5}$ Rumeau, M., Persin, F., Sciers, V., Persin, M., Sarrazin, J., J. Mem. Sci, Z3, 313-322. (1992) 